Document downloaded from:

http://hdl.handle.net/10251/64033

This paper must be cited as:

Saez, S.; Fasciani, C.; Stamplecoskie, KG.; Gagnon, LB.; Mah, T.; Marín García, ML.; Alarcon, El.... (2015). Photochemical synthesis of biocompatible and antibacterial silver nanoparticles embedded within polyurethane polymers. Photochemical \&amp; Photobiological Sciences Photochemical and Photobiological Sciences. 14(4):661-664. doi:10.1039/c4pp00404c.

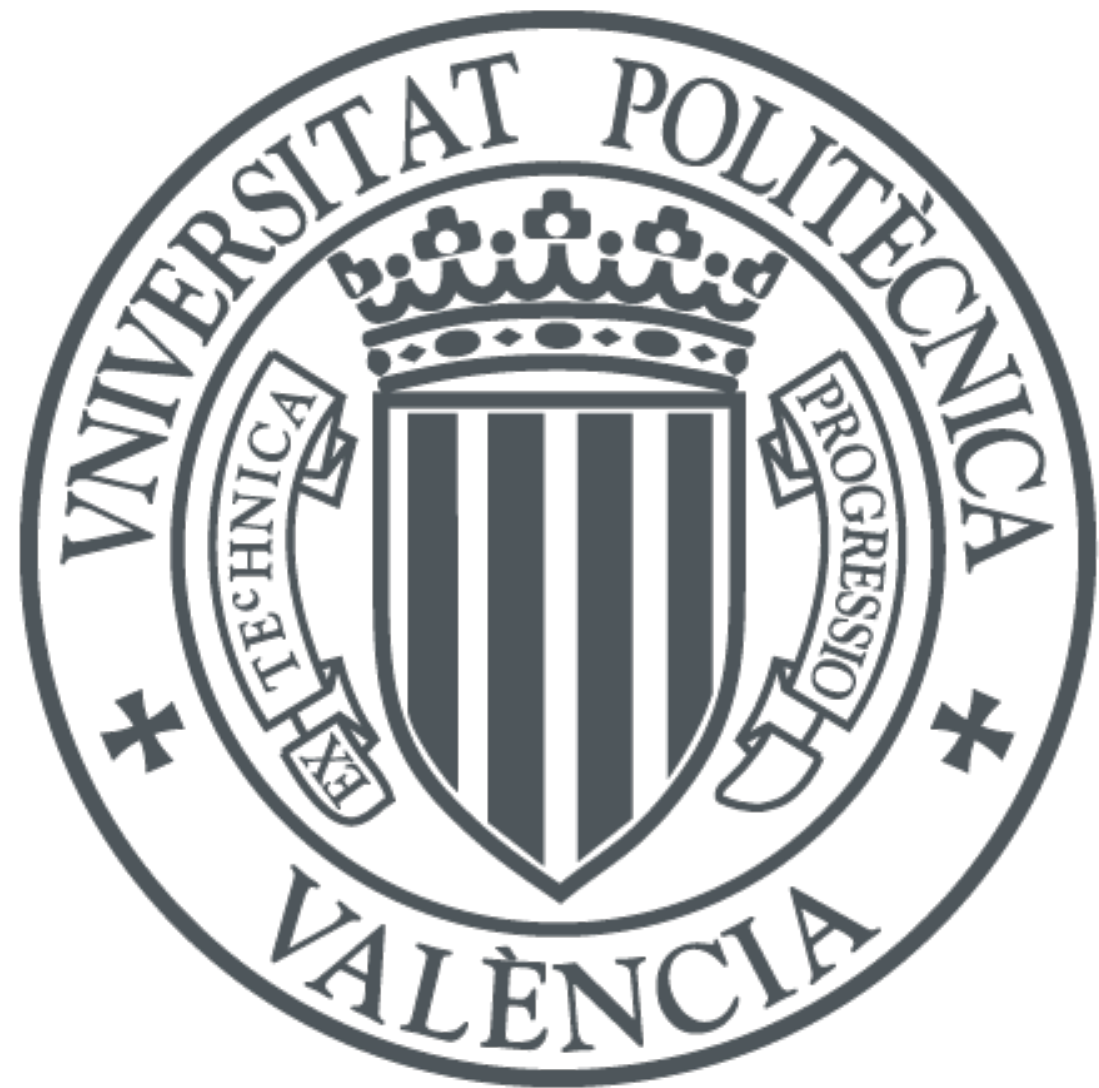

The final publication is available at

http://dx.doi.org/10.1039/c4pp00404c

Copyright Royal Society of Chemistry

Additional Information 


\title{
Photochemical synthesis of biocompatible and antibacterial silver nanoparticles embedded within polyurethane polymers
}

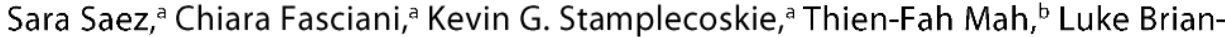 \\ Patrick Gagnon, ${ }^{b}$ M. Luisa Marin, ${ }^{* a, c}$ Emilio I. Alarcon ${ }^{*}$ and Juan C. Scaiano ${ }^{* a}$
}

In-situ light triggered synthesis of silver nanoparticles was employed for their incorporation within the polymeric matrices of medical grade polyurethane. The resulting materials showed improved antibacterial and antibiofilm activities against Pseudomonas aeruginosa with negligible toxicity for human primary skin cells and erythrocytes.

Synthetic polymers had played a pivotal role in the advancement of the biomedical sciences allowing, for example, the fabrication of coating agents, synthetic bio-replacements, and ultimately catheters. However, biofilm indwelling still presents one of the main limitations for the safe and long-term use of biomedical devices including polymer based heart valves and intracorporeal catheters.1,2 This is further aggravated in immunosuppressed individuals like children, and the elderly population;3-5 where catheter-related bloodstream infection (CR-BSI) can be life threatening. Thus, although avoiding contamination during the catheter insertion and post-care of the line are the cornerstone of CR-BSI prevention; improving the antibiofilm ability of intracorporeal catheters would also help to reduce the number and severity of CR-BSI.

Considerably efforts have been done in this field, where, for example, antibiotic-impregnated (e.g. minocycline /rifampicin), coatedcatheters (e.g. chlorhexidine-silver sulfadiazine), and antibiotic lock devices have been fabricated (for a complete review see ref5); they generally6,7 have failed at providing dual protection against Gram $(+)$ and (-) bacteria.4 Although silver impregnation of polyurethane catheters has proven not to be efficient at reducing CR-BSI risks. 8 Silver nanoparticles bear the potential to overcome this, as they display wide antibacterial spectra against both Gram (+) and (-) strains9,10 and as reported by our research group, stable-silver nanoparticles (AgNP) exceed ionic silver as antibacterial agent with non-toxic side effects for primary cells.11-14 Embedding of premade AgNP and/or in-situ thermal reduction of silver ions within water borne polyurethane matrices has been used.15-1718,19 A methodology able to form AgNP within a suitable polyurethane polymer, avoiding harsh experimental conditions has not been reported. In the present communication, we report the lightmediated synthesis of AgNP embedded within polyurethane (PU) films (AgNP@PU). The resulting material kept the physical properties of the original PU catheter, was biocompatible for human skin fibroblasts, shown non-hemolytic activity and proven to control the proliferation and extent of biofilm formation for the opportunistic Pseudomonas aeruginosa bacteria.

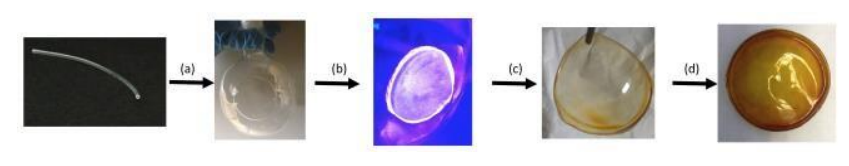

Scheme 1. Main steps involved in the preparation of AgNP@PU. (a) PU medical grade catheter $(350 \mathrm{mg}$ ) was dissolved in THF $(6.0 \mathrm{~mL})$ and a solution of AgNP precursors $(10 \mathrm{~mL})$ containing $1-2959(0.1 \mathrm{mmol}), \mathrm{CF}_{3} \operatorname{COOAg}(0.1 \mathrm{mmol})$ and cyclohexylamine $(1.0 \mathrm{mmol})$ were mixed in a Petri dish and left to dry for 24 hours in dark. The material was then introduced in a round bottom quartz flask with a septum (b) Vacumm- $\mathrm{N}_{2}$ steps were made my means of a Schlenk line and irradiated with UVA for 60 seconds under the $\mathrm{N}_{2}$ atmosphere; (c) The film was thoroughly washed with ethanol $(50 \mathrm{~mL} \times$ three times); (d) Final washed was carried out with PBS ( $25 \mathrm{~mL} \times$ twelve times).

Scheme 1 summarizes the main steps involved in the photochemical preparation for the materials described here. Debris and byproducts from the synthesis were successfully removed with sequential ethanol washes (Fig. S1). Initial experiments carried out using different total concentrations of silver showed that only at $>7.7 \mathrm{mg}$ $\mathrm{Ag} / \mathrm{g} \mathrm{PU}$, the materials had antimicrobial properties. In this communication we will present and discuss the results obtained for the AgNP@PU containing 15 mg Ag/g PU.

Silver surface plasmon band (AgNP-SPB, see Fig. 1) was observed $24 \mathrm{~h}$ after irradiation. This suggests slow nucleation of the nascent silver atoms generated within the PU film during the UVA exposure. The 
presence of green fluorescence observed in the freshly prepared films upon UVA excitation, agrees well with the initial formation of silver clusters that slowly nucleates to form nanoparticles (Fig. S2).20,21 AgNP-SPB had been formed, it was retained after successive washes with PBS buffer, see Fig. S3. Note that the yellow colour is stable for at least up to two years.

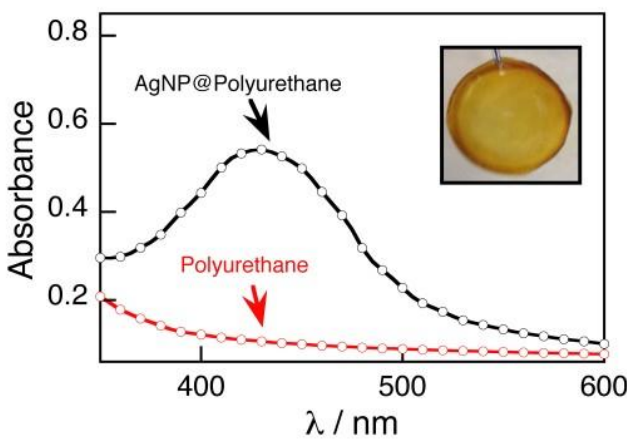

Figure 1. Representative absorption spectra for medical grade PU films $(250 \pm 50$ $\mu \mathrm{m}$ thickness, red circles) or AgNP@PU (black circles). The inset image corresponds to a picture of AgNP@PU ( $5 \mathrm{~cm}$ diameter). All measurements were carried out at room temperature using $6 \mathrm{~mm}$ diameter circular pieces.

Cryo-SEM images for the AgNP@PU films reveal the presence of silver metal nanostructures ( $<500 \mathrm{~nm}$ in average) on both surfaces (Fig. 2A) and within the material (Fig. 2B). Further, the incorporation of the nanostructures within the polymer did not produce significant changes on both Tg and FT-IR specta of the polymer, see Table 1. This indicates minimal modifications on the supramolecular structure of polymer upon AgNP incorporation.

Table 1. Selected properties for AgNP@PU materials prepared in this work.

\begin{tabular}{|c|c|c|}
\hline Sample code & $\mathrm{T}_{\mathrm{g}} /{ }^{\circ} \mathrm{C}$ & FT-IR $\left(\mathrm{cm}^{-1}\right)^{\dagger \dagger}$ \\
\hline Control PU & $-78 \pm 2.0$ & $\begin{array}{c}3380-3225 \mathrm{~m}\left(-\mathrm{CO}-\mathrm{NH}-\text { and } \mathrm{R}_{2-}-\right. \\
\mathrm{NH}) ; 2910 \text { and } 2850 \mathrm{~s}(\mathrm{R} 2-\end{array}$ \\
\hline & & $\left.\mathrm{CH}_{2}\right) ; 1720$ s $\left(\mathrm{R}-\mathrm{CO}-\mathrm{O}-\mathrm{N}-\mathrm{R}_{2}\right)$ \\
\hline AgNP@PU-1 ${ }^{\dagger}$ & $-77 \pm 1.0$ & $\begin{array}{c}3375-3220 \mathrm{~m}\left(-\mathrm{CO}-\mathrm{NH}-\text { and } \mathrm{R}_{2-}\right. \\
\mathrm{NH}) ; 2915 \text { and } 2860 \mathrm{~s}(\mathrm{R} 2- \\
\left.\mathrm{CH}_{2}\right) ; 1725 \mathrm{~s}\left(\mathrm{R}-\mathrm{CO}-\mathrm{O}-\mathrm{N}-\mathrm{R}_{2}\right)\end{array}$ \\
\hline
\end{tabular}

AgNP@PU-2 $2^{\dagger} \quad-78 \pm 1.0$

$\dagger$ AgNP@PU-1 and 2 were prepared using 15 mg Ag/g PU but for the -1 sample the UVA exposure time was $60 \mathrm{~s}$ while for -2 only $40 \mathrm{~s}$ were employed. †† Signal intensity strong (s) and medium (m).
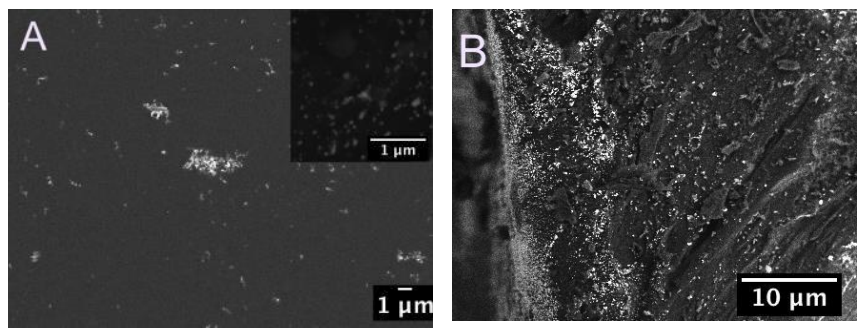

Figure 2. (A) Representative Cryo-SEM image obtained on the surface of a AgNP@PU film (15 mg Ag/g PU). Metal silver appears as white spots. Inset shows a selected area of the polymer with a higher zoom. (B) Cryo-SEM image of a cross section of a AgNP@PU film that was cut for the SEM imaging. The left side of the image shows the top edge for the film.

To determine the impact of AgNP on the material toxicity, cell proliferation of primary skin fibroblasts as well as hemolytic activity for AgNP@PU were carried out. Fig. 3 summarizes the results for cell proliferation (Fig. 3A) and hemolysis of human erythrocytes (Fig. 3B). Those results indicate that AgNP incorporation did not alter the biocompatibility of the medical grade PU polymer. Similar results have been reported for waterborne polyurethanes containing silver nanoparticles.15 Interestingly, the data obtained for the hemolysis of human erythrocytes reveal that the incorporation of AgNP reduces the basal hemolytic level of PU films $(p<0.5)$, see Fig. 3B. This could be attributed to a lower bacteria basal level adsorbed onto the material surface upon incorporation of the AgNP, see below.
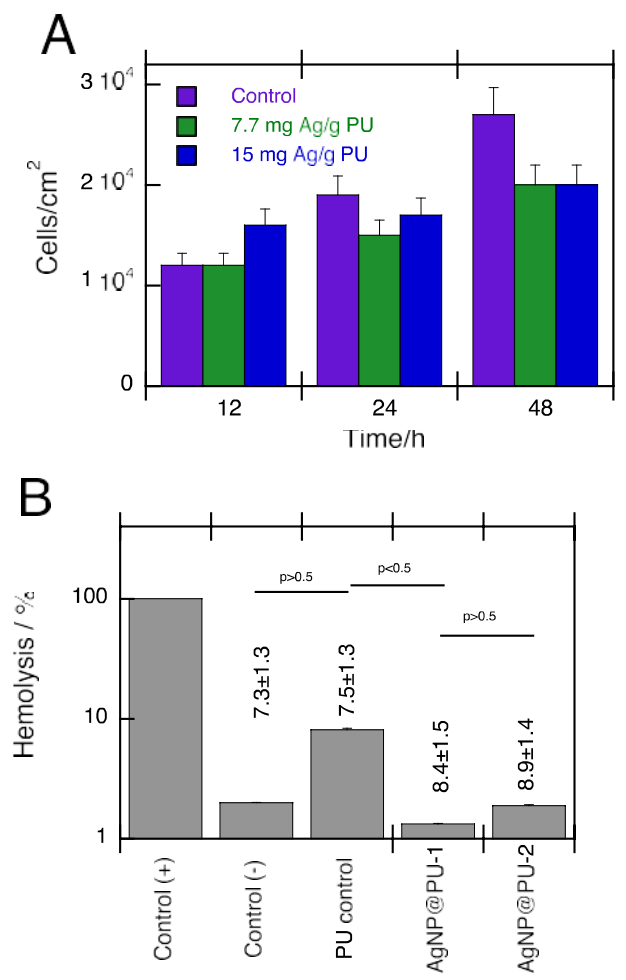

Figure 3. (A) Human skin fibroblasts cell number measured at different time intervals after cell seeding on PU films without (control) or containing two different silver concentrations ( 7.7 and $15 \mathrm{mg} \mathrm{Ag} / \mathrm{g} \mathrm{PU}$ ). Experiments were carried out by quadruplicated. (B) Hemolysis percentage for human erythrocytes incubated for $24 \mathrm{~h}$ at $25^{\circ} \mathrm{C}$ in the presence of polyurethane films without AgNP (PU control) or containing 15 mg Ag/g PU (AgNP@PU-1 or AgNP@PU-2, see footnote Table 1). Controls (+) and (-) correspond to experiments where the cells were completely hemolyzed using sonication and for cells incubated without any additive/polymer, respectively. The numbers on the top of the bars are the cell number density $\left(10^{6}\right.$ cells $\left./ \mathrm{mL}\right)$ measured in the cell suspension after the $24 \mathrm{~h}$ incubation. The $\mathrm{p}$ values correspond to Student two tails $t$ statistic analyses that were carried put for the cell density values. Experiments were carried out by quadruplicate and cell counting values measured in duplicate of each independent sample.

As mentioned before, biofilm formation is a major problem in biomedical devices and in catheters in general. Formation of those bacteria "rafts" is, among other reasons, the main responsible for the development of antibiotic resistance in bacteria propulation. 
Pseudomonas aeruginosa, particularly, is a Gram (-) bacteria species that is directly involved in the formation and control of biofilms on skin burns and biomedical devices.1 Notably, our AgNP@PU polymers were able to control the proliferation of Pseudomonas aeruginosa (PA14) as seen in Fig. 4 top for 18 and 24h. Counting of the survival colonies after $24 \mathrm{~h}$, see inset Fig. 4, indicate that AgNP@PU have bacteriostatic behaviour for Pseudomonas aeruginosa proliferation under our experimental conditions. Further, experiments carried out to analysing the number of colonies formed on the polyurethane surfaces for PU and AgNP@PU of PA14 biofilms indicated that the polymers containing AgNP are statistically less prone $(\approx 50 \%)$ to the formation of PA14 biofilm formation, see Figure 4 bottom.
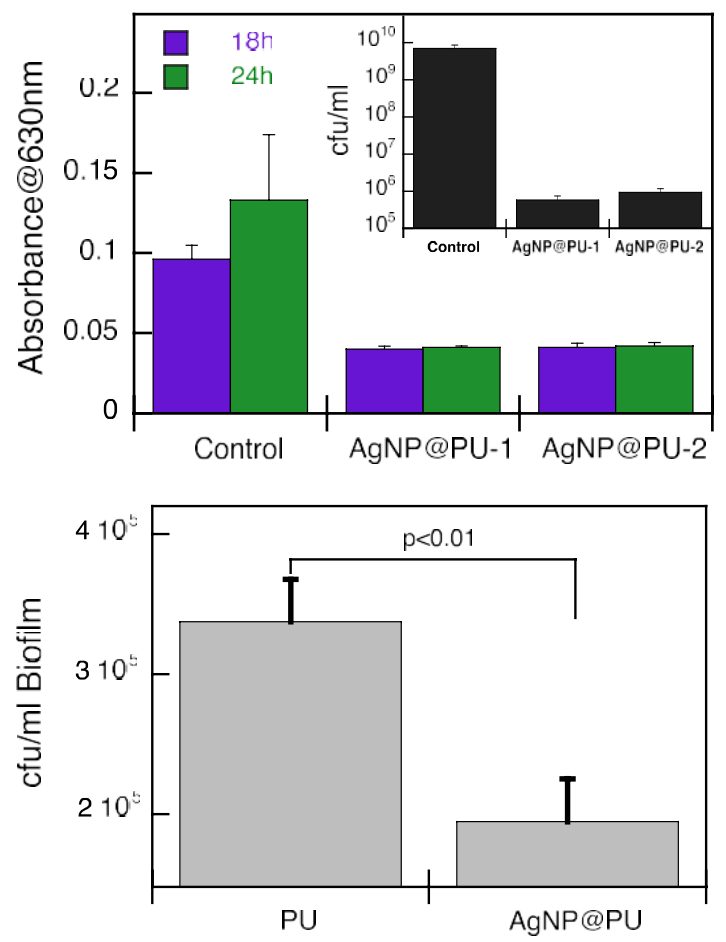

Figure 4. (Top) $630 \mathrm{~nm}$ light scattering expressed as absorption measured after 18 or $24 \mathrm{~h}$ incubation at $37^{\circ} \mathrm{C}$ of Pseudomonas aeruginosa cultures at initial densities of $1 \times 10^{5} \mathrm{cfu} / \mathrm{mL}$ in enriched arginine cell culture medium (M63). Error bars correspond to the standard deviation from four independent samples. Inset: Survival bacteria colonies sampled at $24 \mathrm{~h}$ incubation for the control sample (PU) or for the films containing silver nanoparticles (AgNP@PU). (Bottom) Colony forming units (cfu) of PA14 biofilms grown on polyurethane films without ot with AgNP (PU and AgNP@PU respectively). PA14 biofilms were grown on $11 \mathrm{~mm} P U(n=19)$ and PU + AgNP $(n=17)$ discs for 16.5 hours through an $\mathrm{ALI}$ assay at $37^{\circ} \mathrm{C}$. Biofilm cells were removed from the tablets via sonication before being enumerated by a spot titer assay. After four biological replicates, the colony forming units were averaged. Error bars correspond to the standard error. The corresponding $\mathrm{p}$-value for a two-sided Student's t-test comparing the means of the two populations is $<0.01$

\section{Conclusions}

In summary, we have developed a simple approach for the synthesis of silver nanoparticles within a polyurethane matrix. Incorporation of the nanoparticles within the material did not affect the physical properties of the material or its biocompatibility. However, the presence of silver nanoparticles in the polymer confers it antimicrobial and antibiofilm properties against the growing of Pseudomonas aeruginosa. Although further testing of this new hybrid polymer is needed before any translational use, the use of this material in the fabrication of catheters and/or as coating agent for medical devices would help to reduce their risk CR-BSI.

\section{Acknowledgements}

The authors would like to thank Mr. Michel Grenier and Mr. Christopher McTiernan for his help taking some of the pictures shown in this article and his technical support in the hemolysis project. Support for this work is from a Collaborative Health Research Project grant (NSERC/CIHR Canada) to JCS, NSERC's CREATE program. M. L. Marin thanks the Spanish Ministerio de Educacion, Cultura y Deporte (Programa Salvador de Madariaga) for its financial support. EIA dedicates this work to the memory of Alexander Yu Nielsen who inspired him to pursue with this research.

\section{Notes and references}

${ }^{a}$ Department of Chemistry and Centre for Catalysis Research and Innovation, University of Ottawa, Ottawa, Ontario, K1N 6N5 Department of Biochemistry, Microbiology and Immunology

${ }^{b}$ Department of Biochemistry, Microbiology and Immunology, Faculty of Medicine, University of Ottawa, Ottawa, Canada

${ }^{c}$ Instituto Universitario Mixto de Tecnología Química (UPV-CSIC),

Universitat Politècnica de València, Avenida de los Naranjos s/n, 46022 Valencia, Spain.

†Current address: Bio-Nanomaterials and Chemistry Laboratory, University of Ottawa Heart Institute, 40 Ruskin street, Ottawa Ontario, Canada K1Y 4W7

*Corresponding author: scaiano@photo.chem.uottawa.ca; ealarcon@ottawaheart.ca; marmarin@qim.upv.es

Electronic Supplementary Information (ESI) available: [details of any supplementary information available should be included here]. See DOI: $10.1039 / \mathrm{c} 000000 \mathrm{x} /$

(1) Donlan, R. M. Emerg. Infect. Dis. 2001, 7, 277.

(2) Stickler, D. J. Biofouling 1996, 9, 293.

(3) Pittet, D.; Tarara, D.; Wenzel, R. P. JAMA 1994, 271, 1598.

(4) Darouiche, R. O.; Raad, I. I.; Heard, S. O.; Thornby, J. I.; Wenker, O. C.; Gabrielli, A.; Berg, J.; Khardori, N.; Hanna, H.; Hachem, R.; Harris, R. L.; Mayhall, G. N. Eng. J. Med. 1999, 340, 1.

(5) Janum, S.; Zingg, W.; Classen, V.; Afshari, A. Crit. Care 2013, 17, 12 .

(6) Raad, I.; Mohamed, J. A.; Reitzel, R. A.; Jiang, Y.; Raad, S.; Al Shuaibi, M.; Chaftari, A. M.; Hachem, R. Y. Antimicrob. Agents Chemother. 2012, 56, 935.

(7) Jamal, M. A.; Rosenblatt, J. S.; Hachem, R. Y.; Ying, J.; Pravinkumar, E.; Nates, J. L.; Chaftari, A. M. P.; Raad, II. Antimicrob. Agents Chemother. 2014, 58, 1179.

(8) Bong, J. J.; Kite, P.; Wilco, M. H.; McMahon, M. J. J. Clin. Pathol. 2003, 56, 731 .

(9) Varner, K. E.; El-Badawy, A.; Feldhake, D.; Venkatapathy, R. "State-Of-The-Science Review: Everything NanoSilver and More," U.S. Environmental Protection Agency, 2010.

(10) Eckhardt, S.; Brunetto, P. S.; Gagnon, J.; Priebe, M.; Giese, B.; Fromm, K. M. Chem. Rev. (Washington, DC, U. S.) 2013, 113, 4708. 
(11) Alarcon, E. I.; Udekwu, K.; Skog, M.; Pacioni, N. L.; Stamplecoskie, K. G.; Gonzalez-Bejar, M.; Polisetti, N.; Wickham, A.; Richter-Dahlfors, A.; Griffith, M.; Scaiano, J. C. Biomaterials 2012, 33, 4947.

(12) Alarcon, E. I.; Bueno-Alejo, C. J.; Noel, C. W.; Stamplecoskie, K. G.; Pacioni, N. L.; Poblete, H.; Scaiano, J. C. J. Nanopart. Res. 2013 , $15,1374$.

(13) Simpson, M. J.; Poblete, H.; Griffith, M.; Alarcon, E. I.; Scaiano, J. C. Photochem. Photobiol. 2013, 89, 1433.

(14) Vignoni, M.; Weerasekera, H. d. A.; Simpson, M. J.; Phopase, J.; Mah, T.-F.; Griffith, M.; Alarcon, E.; Scaiano, J. C. Nanoscale 2014, 10.1039/C4NRO1284D

(15) Hsu, S.-h.; Tseng, H.-J.; Lin, Y.-C. Biomaterials 2010, 31, 6796.

(16) Liu, H. L.; Dai, S. A.; Fu, K. Y.; Hsu, S. H. Int. J. Nanomedicine 2010, 5, 1017.

(17) Crespo, J.; García-Barrasa, J.; López-de-Luzuriaga, J.; Monge, M.; Olmos, M. E.; Sáenz, Y.; Torres, C. J. Nanopart. Res. 2012, 14,1.

(18) Gao, J.; Qu, R.; Tang, B.; Wang, C.; Ma, Q.; Sun, C. J. Nanopart. Res. 2011, 13, 5289.

(19) Roohpour, N.; Moshaverinia, A.; Wasikiewicz, J. M.; Paul, D.; Wilks, M.; Millar, M.; Vadgama, P. Biomed. Mater. 2012, 7, 015007.

(20) Scaiano, J. C.; Netto-Ferreira, J. C.; Alarcon, E.; Billone, P.; Bueno Alejo, C. J.; Crites, C.-O. L.; Decan, M.; Fasciani, C.; GonzálezBéjar, M.; Hallett-Tapley, G.; Grenier, M.; McGilvray, K. L.; Pacioni, N. L.; Pardoe, A.; René-Boisneuf, L.; Schwartz-Narbonne, R.; Silvero, M. J.; Stamplecoskie, K.; T-S., W. IUPAC 2011, 83,913.

(21) Maretti, L.; Billone, P. S.; Liu, Y.; Scaiano, J. C. J. Am. Chem. Soc. 2009, 131, 13972. 